\title{
Separation of Cyclic Dipeptides (Diketopiperazines) from Their Corresponding Linear Dipeptides by RP-HPLC and Method Validation
}

\author{
Mareike Perzborn, Christoph Syldatk, and Jens Rudat \\ Institute of Process Engineering in Life Sciences, Section II: Technical Biology, Karlsruhe Institute of Technology (KIT), \\ 76131 Karlsruhe, Germany \\ Correspondence should be addressed to Mareike Perzborn; mareike.perzborn@kit.edu
}

Received 1 September 2012; Accepted 18 November 2012

Academic Editor: Toyohide Takeuchi

Copyright (C) 2013 Mareike Perzborn et al. This is an open access article distributed under the Creative Commons Attribution License, which permits unrestricted use, distribution, and reproduction in any medium, provided the original work is properly cited.

Simple, rapid, sensitive, precise, and accurate methods for detection and separation of seven diketopiperazines (DKPs), cyclo(Gly-Gly), cyclo(DL-Ala-DL-Ala), cyclo(L-Asp-L-Phe), cyclo(L-Asp-L-Asp), cyclo(Gly-L-Phe), cyclo(L-Pro-L-Tyr), and cyclo(L-Arg-L-Arg), from their corresponding linear dipeptides and related amino acids L-Phe and L-Tyr by reversed-phase highperformance liquid chromatography (RP-HPLC) were established. Moreover, for the racemic DKP cyclo(DL-Ala-DL-Ala) and dipeptide DL-Ala-DL-Ala, separation of the diastereomers was achieved. All methods can be performed within 15 min. For all DKPs, dipeptides, and amino acids, linear ranges with correlation coefficients $R^{2}$ greater than 0.998 were determined. Lowest limits of detection were found to be between 0.05 and $10 \mathrm{nmol}$ per $10 \mu \mathrm{L}$ injection, depending on the substance. For all tested substances intrarun and interrun precision ranged from 0.5 to $4.7 \%$ and 0.7 to $9.9 \%$ relative standard deviation, and accuracy was between -4.2 and $8.1 \%$ relative error. Short-term and freeze-thaw stabilities were $93 \%$ or greater for all substances. Recovery rate after heat treatment was determined to be at least $97 \%$. These methods will be useful for quantitative determination of DKPs and their potential biodegradation products: dipeptides and amino acids.

\section{Introduction}

Diketopiperazines (DKPs) are the smallest possible cyclic peptides composed of two $\alpha$-amino acids. They are abundant natural compounds produced by various bacteria like Streptomyces sp. [1], Pseudomonas aeruginosa [2], or Lactobacillus plantarum [3], fungi, e.g., Aspergillus flavus [4] or Alternaria alternata [5], and marine sponges like Dysidea herbacea [6]. Recently, the interest in this substance class has increased due to their immense bioactivities including antibacterial activity [7], antifungal function [3], cytotoxicity [4], phytotoxicity [5], and inhibition of plasminogen activator inhibitor-1 [8]. DKPs were shown to act as quorum sensing molecules; e.g., cyclo(L-Pro-L-Tyr), used in this study, was identified in culture supernatant of Pseudomonas aeruginosa and was identified as an activator of an $\mathrm{N}$-acylhomoserine lactone biosensor [2]. Besides their widespread biosynthesis in nature, DKPs occur as chemical degradation products of, for example, amoxicillin, an aminopenicillin antibiotic [9], neuropeptide substance $P$ [10], angiotensin converting enzyme inhibitor enalapril [11], or the sweetener aspartame with cyclo(L-Asp-L-Phe) as degradation product [12-17]. Amoxicillin and especially its degradation products can be detected in aquatic environment and food of animal origin, thus they are under discussion as a health problem due to their allergenic potential [9]. Analysis of these compounds can be performed with HPLC-MS/MS [9] or UHPLC-MS/MS [18]. Enalapril and two degradation products are determined with RP-HPLC and detection at $215 \mathrm{~nm}$ [11]. Aspartame and its degradation products can be analyzed via RP-HPLC and detection of peptide bond at $195 \mathrm{~nm}$ [12], $200 \mathrm{~nm}$ and $220 \mathrm{~nm}$ [13] or $210 \mathrm{~nm}$ [14], capillary electrophoresis and detection at $214 \mathrm{~nm}$ [15], HPLC coupled with MS/MS [16] or analysis of trimethylsilyl derivatives with GC [17]. Cyclo(Gly-Gly) and Gly are separated by RP-HPLC and detected at $200 \mathrm{~nm}$ [19]. Thus, there are some analysis methods of selected 
DKPs available, but to the best of our knowledge there is no publication of a comprehensive study for separation of DKPs and their corresponding linear dipeptides and amino acids and method validation. However, this would be of great interest for studies on microbial, enzymatical, and chemical degradation of this biologically active substance class. Until now, there are only few bacterial strains reported which can hydrolyze DKPs to the corresponding linear dipeptides. One strain is Paenibacillus chibensis (DSM 329) hydrolyzing the aspartame degradation product cyclo(L-Asp-L-Phe) [20]. This strain was chosen as biological matrix for method validation in this work.

The aim of this study was to establish rapid methods for detection and separation of seven selected DKPs from their corresponding dipeptides and in some cases the amino acids. Moreover, these methods were validated for sensitivity, linearity, precision, accuracy, stability, and recovery.

\section{Experimental}

2.1. Chemicals and Reagents. The standards cyclo(L-AlaL-Ala), L-Asp-L-Phe, L-Phe-L-Asp, cyclo(L-Pro-L-Tyr), L-ProL-Tyr, L-Tyr-L-Pro, cyclo(L-Asp-L-Asp), L-Asp-L-Asp, cyclo(Gly-L-Phe), Gly-L-Phe, L-Phe-Gly, and L-Arg-L-Arg acetate salt were purchased from Bachem Holding (Bubendorf, Switzerland), cyclo(Gly-Gly), Gly-Gly, and DL-Ala-DL-Ala were obtained from TCI Europe N.V. (Zwyndrecht, Belgium), cyclo(DL-Ala-DL-Ala), L-Ala-L-Ala, cyclo(L-Asp-L-Phe) and L-Phe were received from SigmaAldrich (St. Louis, USA), L-Tyr was purchased from Carl Roth Corporation (Karlsruhe, Germany), and cyclo(L-Arg-L-Arg) acetate salt was provided by Taros Chemicals Corporation (Dortmund, Germany).

Methanol ROTISOLV HPLC Gradient Grade ( $\mathrm{MeOH})$, peptone from casein, $\mathrm{K}_{2} \mathrm{HPO}_{4}, \mathrm{KH}_{2} \mathrm{PO}_{4}, \mathrm{Na}_{2} \mathrm{HPO}_{4} \times 2 \mathrm{H}_{2} \mathrm{O}$, $\mathrm{NaH}_{2} \mathrm{PO}_{4} \times 2 \mathrm{H}_{2} \mathrm{O}$ were supplied by Carl Roth Corporation (Karlsruhe, Germany). Yeast extract was obtained from Becton, Dickinson and Company (Franklin Lakes, USA). $\mathrm{MgSO}_{4} \times 7 \mathrm{H}_{2} \mathrm{O}$ was purchased from Sigma-Aldrich (St. Louis, USA).

2.2. Instrumentation and Chromatographic Conditions. The HPLC analysis was performed using an Agilent 1200 system (Agilent Technologies, Santa Clara, USA) equipped with a quaternary pump, a degasser, an autosampler, a thermostated column compartment, and a variable wavelength detector. Separations were carried out with isocratic elution on a reversed-phase column NUCLEODUR Sphinx RP (4.6 mm ID $\times 250 \mathrm{~mm}, 5 \mu \mathrm{m}$ particle size, Macherey-Nagel Corporation, Düren, Germany) connected with a $\mathrm{C}_{18}$ security guard column $(3.0 \mathrm{~mm}$ ID $\times 4 \mathrm{~mm}$, Phenomenex, Torrance, USA). The mobile phase consisted of varying ratios of $\mathrm{MeOH}$ and $20 \mathrm{mM}$ sodium phosphate buffer ( $\mathrm{pH}$ 5.5). The buffer was filtered through a nitrocellulose membrane with $0.22 \mu \mathrm{m}$ pore size (Merck Millipore, Darmstadt, Germany). Best separation conditions were investigated by determination of retention time $\left(t_{R}\right)$, separation factor $(\alpha)$, and peak resolution $\left(R_{s}\right)$ for each standard with $10 \%, 20 \%$, and $30 \% \mathrm{MeOH}$. After determination of best separation conditions, the following compositions of mobile phase were used. Separation of cyclo(Gly-Gly) from Gly-Gly, cyclo(DL-Ala-DL-Ala) from DL-Ala-DL-Ala, cyclo(L-Asp-L-Asp) from L-Asp-L-Asp, and cyclo(L-Arg-L-Arg) from L-Arg-L-Arg was done with $10 \% \mathrm{MeOH}$ and $90 \%$ buffer. $20 \% \mathrm{MeOH}$ and $80 \%$ buffer were used to separate cyclo(L-Asp-L-Phe), L-Asp-L-Phe, L-Phe-L-Asp, and L-Phe. With 30\% $\mathrm{MeOH}$ and $70 \%$ buffer cyclo(L-Pro-L-Tyr) was separated from L-Pro-L-Tyr, L-Tyr-L-Pro, and L-Tyr, and cyclo(Gly-L-Phe) from Gly-L-Phe, L-Phe-Gly, and L-Phe. The injection volume was $10 \mu \mathrm{L}$ and detection wavelength was $210 \mathrm{~nm}$. The flow rate was $0.7 \mathrm{~mL} \mathrm{~min}^{-1}$, and the column temperature was set to $20^{\circ} \mathrm{C}$ (for analysis with 10 and $20 \% \mathrm{MeOH}$ ) or to $30^{\circ} \mathrm{C}$ (for $30 \% \mathrm{MeOH}$ ). Differing from these standard conditions cyclo(L-Asp-L-Asp) and L-Asp-L-Asp were separated with $15^{\circ} \mathrm{C}$ column temperature and $0.3 \mathrm{~mL} \mathrm{~min}{ }^{-1}$ flow rate; cyclo(L-Arg-L-Arg) was detected at a wavelength of $268 \mathrm{~nm}$.

Validation of each substance was performed under best separation conditions and run time was $15 \mathrm{~min}$ for each sample.

2.3. Preparation of Standard Solutions. Stock solutions of DKPs, dipeptides, and amino acids were prepared in $50 \mathrm{mM}$ sodium phosphate buffer $(\mathrm{pH} 7.5)$ and stored at $-20^{\circ} \mathrm{C}$. The concentration of each stock solution was adjusted to $50 \mathrm{mM}$, except for $25 \mathrm{mM}$ cyclo(L-Asp-L-Phe), $10 \mathrm{mM}$ cyclo(Gly-LPhe), and $5 \mathrm{mM}$ L-Tyr. These stock solutions were serially diluted and used directly for determination of the linear range. Calibration curves were established based on seven concentrations within the linear range. For method validation the stock solutions were diluted to low, medium, and high concentration and were mixed $(1: 1)$ with crude extract of DSM 329.

2.4. Crude Extract Preparation. Crude extract was prepared from the bacterial strain Paenibacillus chibensis (DSM 329) purchased from German Collection of Microorganisms and Cell Cultures (DSMZ, Braunschweig, Germany). The strain was cultivated in modified complex medium $\left(10 \mathrm{~g} \mathrm{~L}^{-1}\right.$ peptone, $10 \mathrm{~g} \mathrm{~L}^{-1}$ yeast extract, $3 \mathrm{~g} \mathrm{~L}^{-1} \mathrm{~K}_{2} \mathrm{HPO}_{4}, 1 \mathrm{~g} \mathrm{~L}^{-1} \mathrm{KH}_{2} \mathrm{PO}_{4}$, $0.5 \mathrm{~g} \mathrm{~L}^{-1} \mathrm{MgSO}_{4} \times 7 \mathrm{H}_{2} \mathrm{O}$, adjusted to $\mathrm{pH} 7.2$ ) [20] at $30^{\circ} \mathrm{C}$ and $100 \mathrm{rpm}$ for $24 \mathrm{~h}$ until reaching an $\mathrm{OD}_{600}$ of 2.1. Cells were washed three times by centrifugation $(4,816 \times \mathrm{g}, 30 \mathrm{~min}$, $4^{\circ} \mathrm{C}$ ), discarding the supernatant and resuspension in $50 \mathrm{mM}$ sodium phosphate buffer ( $\mathrm{pH} 7.5)$. Washed cell pellet was resuspended in the same buffer to an $\mathrm{OD}_{600}$ of approximately 17. Cells were disrupted by sonication for $25 \mathrm{~min}$ using alternate intervals of $30 \mathrm{sec}$ pulsation on and $30 \mathrm{sec}$ pulsation off and 35\% amplitude (Sonopuls HD 3100 with ultrasonic probe MS 72, Bandelin electronic Corporation, Berlin, Germany). After centrifugation $\left(4,816 \times \mathrm{g}, 30 \mathrm{~min}, 4^{\circ} \mathrm{C}\right)$, the crude extract was inactivated by heating at $90^{\circ} \mathrm{C}(20 \mathrm{~min}, 1,500 \mathrm{rpm})$ with Thermomixer comfort (Eppendorf Corporation, Hamburg, Germany) and centrifuged $\left(24,725 \times \mathrm{g}, 20 \mathrm{~min}, 4^{\circ} \mathrm{C}\right)$. The protein concentration was determined by Bio-Rad Protein Assay (Bio-Rad Laboratories, Hercules, USA) according to 
TABLE 1: Retention factor $(k)$ for DKPs, dipeptides, and amino acids and separation factor $(\alpha)$ and resolution $\left(R_{s}\right)$ of two adjacent peaks at chosen separation conditions.

\begin{tabular}{|c|c|c|c|c|}
\hline Separation conditions & Substance & Retention factor $k$ & Separation factor $\alpha$ & Resolution $R_{s}$ \\
\hline \multirow{10}{*}{$10 \% \mathrm{MeOH}, 20^{\circ} \mathrm{C}, 0.7 \mathrm{~mL} \mathrm{~min}^{-1}$} & Cyclo(Gly-Gly) & 1.03 & \multirow{2}{*}{1.63} & \multirow{2}{*}{5.47} \\
\hline & Gly-Gly & 0.63 & & \\
\hline & Cyclo(L-Ala-D-Ala) & 2.34 & \multirow{2}{*}{1.18} & \multirow{2}{*}{3.26} \\
\hline & Cyclo(L-Ala-L-Ala) and cyclo(D-Ala-D-Ala) & 2.75 & & \\
\hline & L-Ala-L-Ala and D-Ala-D-Ala & 0.67 & \multirow{2}{*}{1.25} & \multirow{2}{*}{1.83} \\
\hline & L-Ala-D-Ala & 0.84 & & \\
\hline & Cyclo(L-Ala-D-Ala) & 2.34 & \multirow{2}{*}{2.79} & \multirow{2}{*}{13.77} \\
\hline & L-Ala-D-Ala & 0.84 & & \\
\hline & Cyclo(L-Arg-L-Arg) & 1.08 & \multirow{2}{*}{1.36} & \multirow{2}{*}{1.55} \\
\hline & L-Arg-L-Arg & 0.79 & & \\
\hline \multirow{2}{*}{$10 \% \mathrm{MeOH}, 15^{\circ} \mathrm{C}, 0.3 \mathrm{~mL} \mathrm{~min}^{-1}$} & Cyclo(L-Asp-L-Asp) & 0.61 & \multirow{2}{*}{1.15} & \multirow{2}{*}{1.04} \\
\hline & L-Asp-L-Asp & 0.53 & & \\
\hline \multirow{6}{*}{$20 \% \mathrm{MeOH}, 20^{\circ} \mathrm{C}, 0.7 \mathrm{~mL} \mathrm{~min}^{-1}$} & Cyclo(L-Asp-L-Phe) & 3.33 & \multirow{2}{*}{1.14} & \multirow{2}{*}{2.31} \\
\hline & L-Phe & 2.93 & & \\
\hline & L-Asp-L-Phe & 2.10 & \multirow{2}{*}{1.40} & \multirow{2}{*}{5.45} \\
\hline & L-Phe & 2.93 & & \\
\hline & L-Asp-L-Phe & 2.10 & \multirow{2}{*}{1.59} & \multirow{2}{*}{5.88} \\
\hline & L-Phe-L-Asp & 1.32 & & \\
\hline \multirow{12}{*}{$30 \% \mathrm{MeOH}, 30^{\circ} \mathrm{C}, 0.7 \mathrm{~mL} \mathrm{~min}^{-1}$} & Cyclo(L-Pro-L-Tyr) & 3.75 & \multirow{2}{*}{2.26} & \multirow{2}{*}{9.44} \\
\hline & L-Tyr-L-Pro & 1.66 & & \\
\hline & L-Tyr-L-Pro & 1.66 & \multirow{2}{*}{1.76} & \multirow{2}{*}{4.23} \\
\hline & L-Tyr & 0.95 & & \\
\hline & L-Pro-L-Tyr & 0.93 & \multirow{2}{*}{1.02} & \multirow{2}{*}{0.22} \\
\hline & L-Tyr & 0.95 & & \\
\hline & Cyclo(Gly-L-Phe) & 4.36 & \multirow{2}{*}{2.31} & \multirow{2}{*}{16.12} \\
\hline & L-Phe-Gly & 1.89 & & \\
\hline & L-Phe-Gly & 1.89 & \multirow{2}{*}{1.01} & 017 \\
\hline & L-Phe & 1.87 & & 0.17 \\
\hline & Gly-L-Phe & 1.84 & 102 & 0.27 \\
\hline & L-Phe & 1.87 & 1.02 & 0.27 \\
\hline
\end{tabular}

Hold-up time $=2.167$ min (manufacturer information).

the manufacturers' instructions. The obtained crude extract was diluted with the described buffer to a final protein concentration of $0.3 \mathrm{mg} \mathrm{mL}^{-1}$.

2.5. Method Validation. The detection of DKPs, dipeptides, and amino acids was validated for sensitivity, linearity, precision, accuracy, stability, and recovery according to the bioanalytical method validation guidelines of the FDA [21]. Validation of each substance was done under best separation conditions, which were determined in this study.

Intrarun precision and accuracy were assessed using five replicates at low, medium, and high concentration, within consecutive runs. Interrun precision was determined using these experimental conditions on three different days. Precision was expressed as relative standard deviation, RSD (\%) = $100 *$ (standard deviation/mean). Accuracy was calculated as relative error, $\mathrm{RE}(\%)=100 *$ (mean measured concentration - true concentration/true concentration). The acceptance limits were set at a maximum of $\pm 15 \%$ at medium and high concentrations and $\pm 20 \%$ at low concentration. For each substance the mean value of low, medium, and high concentrations was calculated for precision and accuracy.
Short-term temperature stability and freeze-thaw stability were determined with freshly spiked samples at low and high concentration in triplicate. Stability was calculated by comparing the peak areas obtained by direct injection, after storage at $21^{\circ} \mathrm{C}$ for $24 \mathrm{~h}$, and after three freeze and thaw cycles. For determination of freeze and thaw stability samples were frozen at $-20^{\circ} \mathrm{C}$ for $24 \mathrm{~h}$, completely thawed and refrozen for $21 \mathrm{~h}$. The freeze-thaw cycle was repeated two times and samples were analyzed on the third cycle.

Recovery was determined by using four replicates at low, medium, and high concentrations. Evaluation was done by comparing the peak areas of samples spiked after heat treatment with samples spiked before heat treatment. For heat treatment samples were incubated at $90^{\circ} \mathrm{C}$ and $1,400 \mathrm{rpm}$ for 10 min using Thermomixer comfort (Eppendorf Corporation, Hamburg, Germany).

\section{Results and Discussion}

3.1. Separation. Best separation conditions of DKPs, their corresponding linear dipeptides, and the amino acids L-Phe and L-Tyr are summarized in Table 1. These two aromatic 


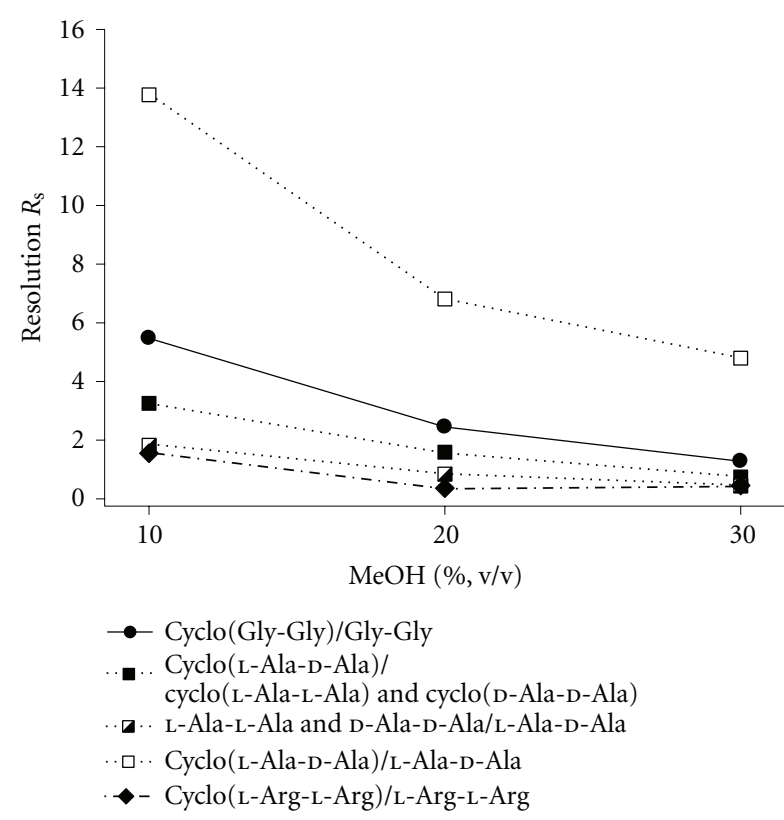

(a)

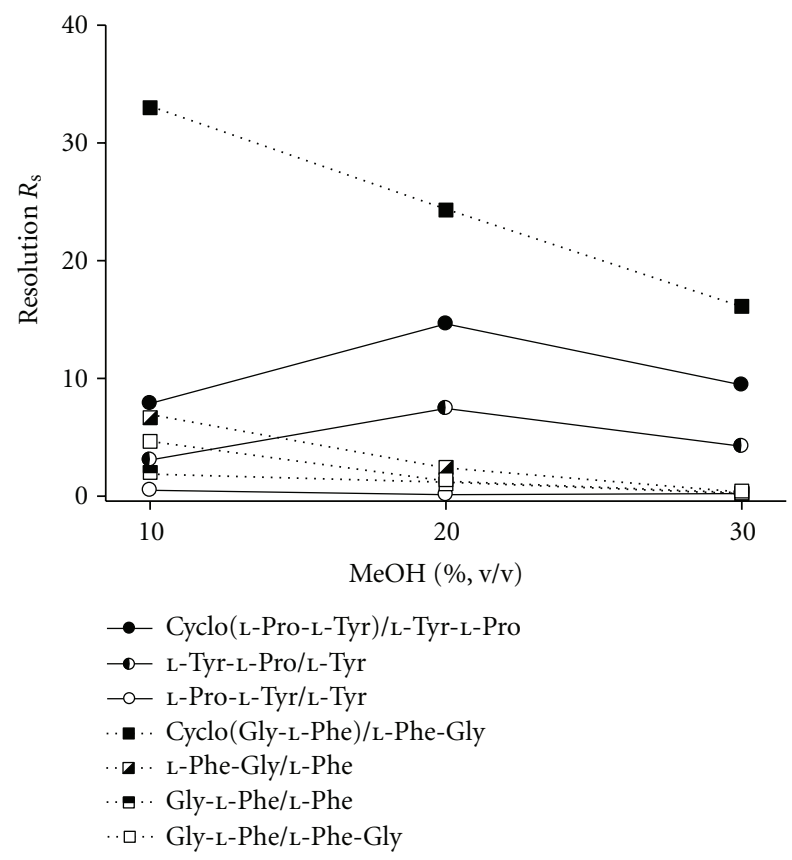

(c)

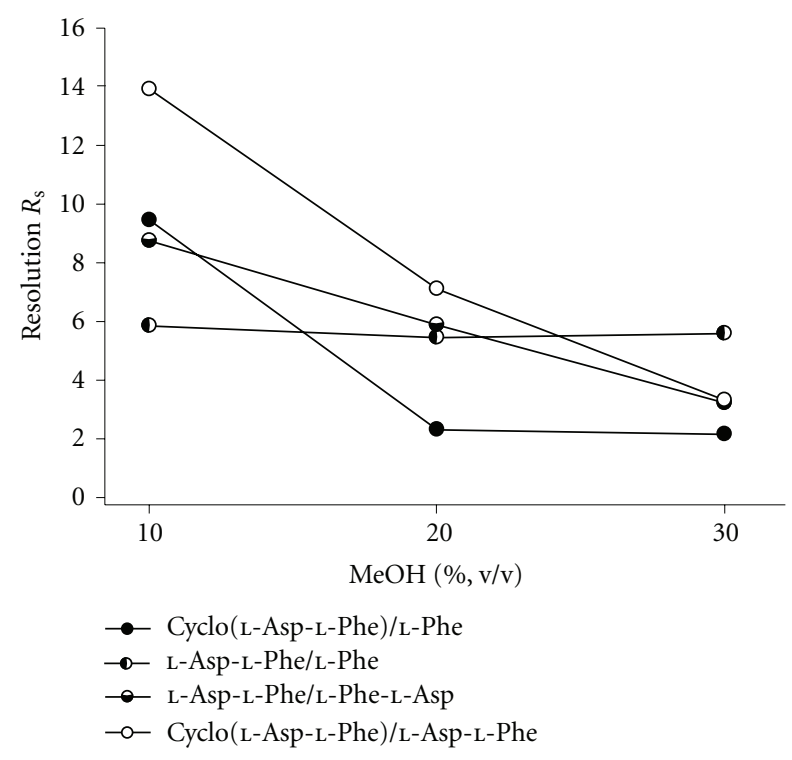

(b)

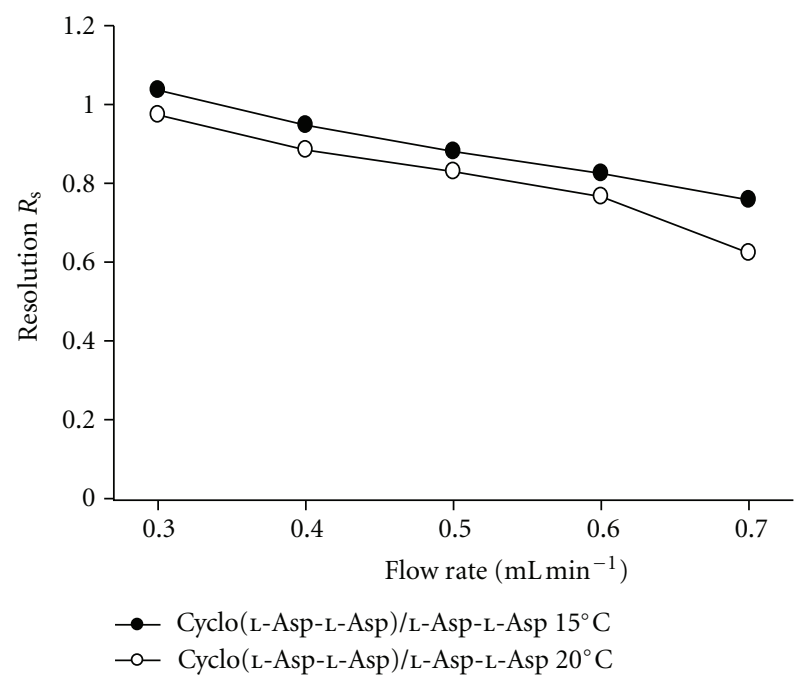

FIGURE 1: Resolution $R_{s}$ of two adjacent peaks of DKPs, dipeptides, and amino acids depending on MeOH concentration (a-c) or flow rate (d); substances with (a) $10 \% \mathrm{MeOH}$, (b) $20 \% \mathrm{MeOH}$, and (c) $30 \% \mathrm{MeOH}$ chosen as best separation conditions; (d) cyclo(L-Asp-L-Asp) and L-Asp-L-Asp at flow rate from 0.3 to $0.7 \mathrm{~mL} \mathrm{~min}^{-1}$ at 15 and $20^{\circ} \mathrm{C}$ column temperature and $10 \% \mathrm{MeOH}$.

amino acids were analyzed due to their detectability at $210 \mathrm{~nm}$.

Separation factors $\alpha$ and peak resolutions $R_{s}$ were calculated for two adjacent peaks at different $\mathrm{MeOH}$ concentrations (Figures 1(a)-1(c)). For some separations the order of peaks changed by altering $\mathrm{MeOH}$ concentration, resulting in variation of peaks which are adjacent.
The aim was to identify a method for each DKP, dipeptide and the two amino acids with resolution greater than 1.5 and longest retention time of maximum $15 \mathrm{~min}$.

For separation of cyclo(Gly-Gly) from Gly-Gly and cyclo(L-Arg-L-Arg) from L-Arg-L-Arg best separation conditions were achieved with $10 \% \mathrm{MeOH}$ mixed with $90 \% 20 \mathrm{mM}$ sodium phosphate buffer $(\mathrm{pH} 5.5), 20^{\circ} \mathrm{C}$ 


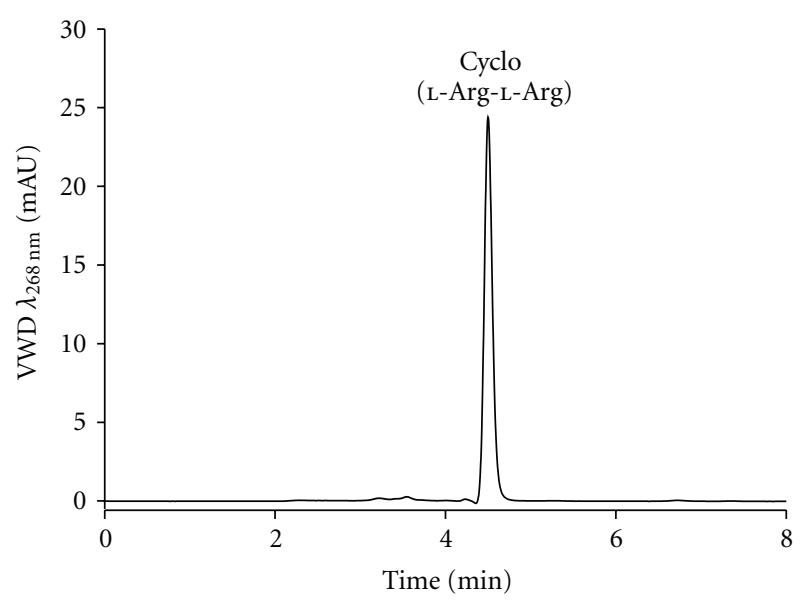

(a)

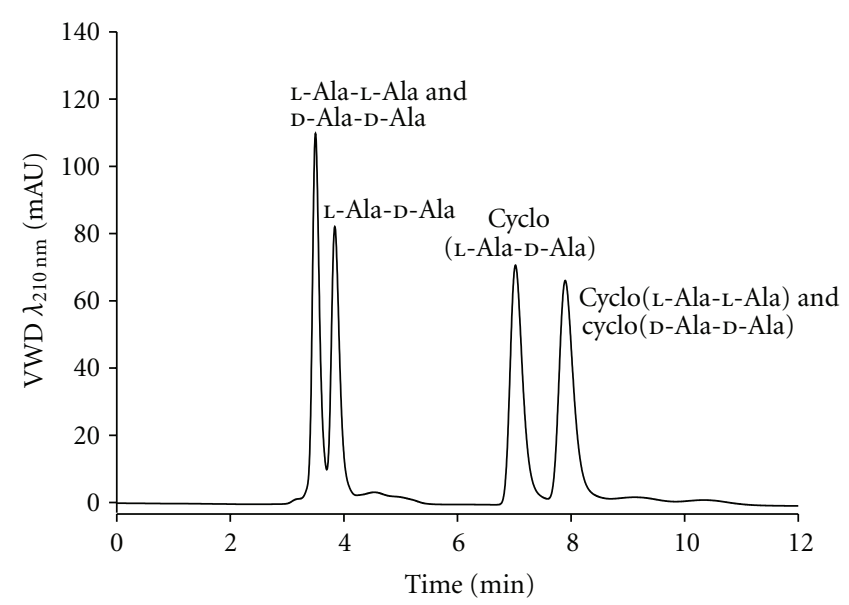

(b)

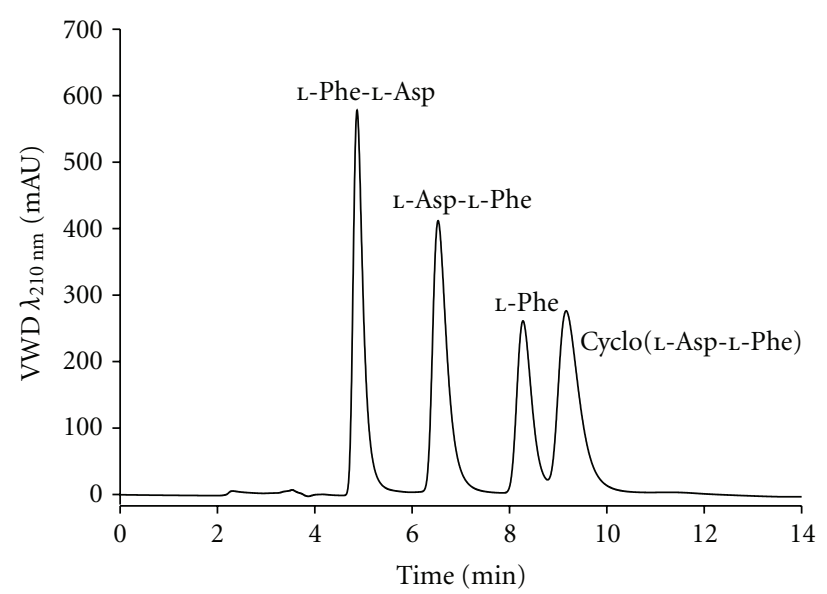

(c)

Figure 2: HPLC chromatograms of $1 \mathrm{mM}$ standards of (a) cyclo(L-Arg-L-Arg) at $10 \% \mathrm{MeOH}, 268 \mathrm{~nm}$; (b) L-Ala-L-Ala and D-Ala-D-Ala, L-Ala-D-Ala, cyclo(L-Ala-D-Ala) and cyclo(L-Ala-L-Ala) and cyclo(D-Ala-D-Ala) at 10\% MeOH, $210 \mathrm{~nm}$; (c) L-Phe-L-Asp, L-Asp-L-Phe, L-Phe and cyclo(L-Asp-L-Phe) at $20 \% \mathrm{MeOH}, 210 \mathrm{~nm}$; all separations were performed at: $20^{\circ} \mathrm{C}$ column temperature and $0.7 \mathrm{~mL} \mathrm{~min}^{-1}$ flow rate.

column temperature, and a flow rate of $0.7 \mathrm{~mL} \mathrm{~min}^{-1}$ (Table 1 , Figure 1(a)). In contrast to all used substances which were measured at a wavelength of $210 \mathrm{~nm}$, cyclo(L-Arg-L-Arg) was detected by absorption of the guanidino groups $(\lambda=268 \mathrm{~nm})$. Detection of cyclo(L-Arg-L-Arg) at $210 \mathrm{~nm}$ resulted in four peaks and it remained unclear which peak belonged to cyclo(L-Arg-L-Arg). On the contrary, detection of cyclo(L-Arg-L-Arg) at $268 \mathrm{~nm}$ showed one symmetric peak (Figure 2(a)).

Best separation of cyclo(DL-Ala-DL-Ala) from corresponding dipeptide DL-Ala-DL-Ala was determined with $10 \%$ $\mathrm{MeOH}$ as well (Table 1, Figure 1(a)). Moreover, for these racemic substances separation of the diastereomers could be performed. Cyclo(L-Ala-D-Ala) was separated from the enantiomeric pair cyclo(L-Ala-L-Ala) and cyclo(D-Ala-D-Ala), and L-Ala-D-Ala was separated from the enantiomeric pair LAla-L-Ala and D-Ala-D-Ala (Figure 2(b)). By measuring the enantiomers cyclo(L-Ala-L-Ala) and L-Ala-L-Ala attribution of the peaks was achieved.
It was not possible to separate cyclo(L-Asp-L-Asp) and L-Asp-L-Asp at $10 \% \mathrm{MeOH}, 20^{\circ} \mathrm{C}$ column temperature, and a

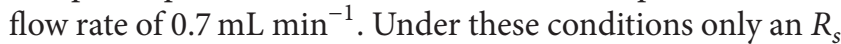
value of 0.62 was determined (Figure $1(\mathrm{~d})$ ). $10 \%$ is the lowest $\mathrm{MeOH}$ concentration which can be used for this column, but by decreasing column temperature to $15^{\circ} \mathrm{C}$ and flow rate to $0.3 \mathrm{~mL} \mathrm{~min}^{-1}$ the resolution was improved to 1.04 (Table 1, Figure 1(d)).

Good separation of cyclo(L-Asp-L-Phe), L-Asp-L-Phe, $\mathrm{L}-\mathrm{Phe}-\mathrm{L}-\mathrm{Asp}$, and $\mathrm{L}-\mathrm{Phe}$ and retention times lower than 15 min were achieved with $20 \% \mathrm{MeOH}, 20^{\circ} \mathrm{C}$ column temperature, and a flow rate of $0.7 \mathrm{~mL} \mathrm{~min}^{-1}$ (Table 1, Figure 2(c)). Even better resolution was obtained with $10 \% \mathrm{MeOH}$ (Figure 1(b)), but under these conditions retention times were longer than $15 \mathrm{~min}$.

For cyclo(L-Pro-L-Tyr), L-Pro-L-Tyr, L-Tyr-L-Pro, and LTyr best separation and short retention times were observed with $30 \% \mathrm{MeOH}, 30^{\circ} \mathrm{C}$ column temperature, and a flow 
TABLE 2: Linear range, linear equation, correlation coefficient $R^{2}$, and limit of quantification (LOQ) for DKPs, dipeptides, and amino acids.

\begin{tabular}{|c|c|c|c|c|}
\hline Substance & $\begin{array}{l}\text { Linear range } \\
(\mathrm{mM})\end{array}$ & Linear equation & $R^{2}$ & $\begin{array}{c}\text { LOQ } \\
\text { (nmol per } 10 \mu \mathrm{L} \text { injection) }\end{array}$ \\
\hline Cyclo(Gly-Gly) & $0.010-5.00$ & $y=1732 x+107$ & 0.9980 & 5.00 \\
\hline Gly-Gly & $0.010-5.00$ & $y=1355 x+124$ & 0.9989 & 10.00 \\
\hline Cyclo(L-Ala-D-Ala) & $0.025-5.00$ & $y=2188 x+93$ & 0.9991 & 5.00 \\
\hline Cyclo(L-Ala-L-Ala) and cyclo(D-Ala-D-Ala) & $0.025-5.00$ & $y=2271 x+96$ & 0.9991 & 0.25 \\
\hline L-Ala-L-Ala and D-Ala-D-Ala & $0.025-5.00$ & $y=1821 x+111$ & 0.9996 & 5.00 \\
\hline L-Ala-D-Ala & $0.025-5.00$ & $y=1642 x+60$ & 0.9996 & 5.00 \\
\hline Cyclo(L-Arg-L-Arg) & $0.100-50.00$ & $y=162 x+5$ & 1.0000 & 1.00 \\
\hline L-Arg-L-Arg & $0.010-10.00$ & $y=1611 x+86$ & 0.9996 & 5.00 \\
\hline Cyclo(L-Asp-L-Asp) & $0.005-2.50$ & $y=6855 x+307$ & 0.9992 & 5.00 \\
\hline L-Asp-L-Asp & $0.010-5.00$ & $y=5192 x+225$ & 0.9990 & 5.00 \\
\hline cyclo(L-Asp-L-Phe) & $0.005-5.00$ & $y=8227 x+162$ & 0.9998 & 0.05 \\
\hline L-Asp-L-Phe & $0.005-5.00$ & $y=8258 x+132$ & 0.9999 & 0.05 \\
\hline L-Phe-L-Asp & $0.005-2.50$ & $y=8389 x+122$ & 0.9994 & 0.50 \\
\hline L-Phe $(20 \% \mathrm{MeOH})$ & $0.005-5.00$ & $y=5845 x+131$ & 0.9997 & 0.10 \\
\hline Cyclo(L-Pro-L-Tyr) & $0.005-5.00$ & $y=8256 x+116$ & 0.9999 & 0.05 \\
\hline L-Pro-L-Tyr & $0.005-2.50$ & $y=7164 x+87$ & 0.9997 & 1.00 \\
\hline L-Tyr-L-Pro & $0.010-10.00$ & $y=6127 x+172$ & 0.9997 & 5.00 \\
\hline L-Tyr & $0.010-2.50$ & $y=4929 x+43$ & 1.0000 & 10.00 \\
\hline Cyclo(Gly-L-Phe) & $0.005-5.00$ & $y=7662 x+165$ & 0.9997 & 0.05 \\
\hline Gly-L-Phe & $0.005-2.50$ & $y=8360 x+106$ & 0.9995 & 0.10 \\
\hline L-Phe-Gly & $0.005-2.50$ & $y=7392 x+109$ & 0.9993 & 0.10 \\
\hline L-Phe $(30 \% \mathrm{MeOH})$ & $0.005-2.50$ & $y=6121 x+60$ & 0.9997 & 0.10 \\
\hline
\end{tabular}

rate of $0.7 \mathrm{~mL} \min ^{-1}$ (Table 1 ). Under these conditions one drawback was that L-Pro-L-Tyr was not separated from L-Tyr $\left(R_{s}=0.22\right)$ (Figure $1(\mathrm{c})$ ); nevertheless, the main aim to separate DKP from dipeptides and amino acid was achieved. The same conditions were chosen for separation of cyclo(Gly-LPhe) from Gly-L-Phe, L-Phe-Gly, and L-Phe (Table 1). Under these conditions separation of cyclo(Gly-L-Phe) from the corresponding dipeptides and L-Phe was possible, but not the separation of the two dipeptides and the amino acid from each other. For separation of all four substances best conditions were $10 \% \mathrm{MeOH}, 20^{\circ} \mathrm{C}$ column temperature and a flow rate of $0.7 \mathrm{~mL} \mathrm{~min}^{-1}$ with $R_{s}=2.01$ for Gly-L-Phe and LPhe, and $R_{s}=4.66$ for Gly-L-Phe and L-Phe-Gly (Figure $1(\mathrm{c})$ ). This resulted in a method time of about $30 \mathrm{~min}$.

All DKPs could be separated from their corresponding dipeptides with a peak resolution $R_{s}$ higher than 1.5, with the exception of cyclo(L-Asp-L-Asp) and L-Asp-L-Asp with $R_{s}$ below 1.5 .

Method validation was done under best separation conditions (see Table 1). The developed methods were validated by using crude extract of Paenibacillus chibensis (DSM 329) spiked with the studied substances. This strain was chosen as biological matrix because of its reported ability to hydrolyze the DKP cyclo(L-Asp-L-Phe) [20].

3.2. Linearity and Sensitivity. The analytical results for linear range, linear equation, correlation coefficient $R^{2}$, limit of detection (LOD) shown as lower limit of linear range and limit of quantification (LOQ) obtained from this investigation are summarized in Table 2.

LOD is in accordance with the lower limit of the linear range and is between $0.005 \mathrm{mM}$ (e.g., cyclo(L-Pro-L-Tyr), cyclo(Gly-L-Phe)) and $0.100 \mathrm{mM}$ for cyclo(L-Arg-L-Arg). The maximum of the linear range varied between $2.50 \mathrm{mM}$ and $50.00 \mathrm{mM}$ depending on the substance. For cyclo(GlyGly) a LOD of $5 \mu \mathrm{g} \mathrm{mL}^{-1}$ was described [19]; this equates $0.04 \mathrm{mM}$, which is higher than the LOD of $0.010 \mathrm{mM}$ for cyclo(Gly-Gly) shown in this study. For cyclo(L-Asp-L-Phe) an LOD of $10 \mathrm{ng}$ per $20 \mu \mathrm{L}$ injection [13] and $2.5 \mathrm{ng}$ per $10 \mu \mathrm{L}$ injection [14] was described. These values equate $0.002 \mathrm{mM}$ 
TABLE 3: Precision, accuracy, stability, and recovery for DKPs, dipeptides, and amino acids in crude extract of DSM 329.

\begin{tabular}{|c|c|c|c|c|c|c|}
\hline Substance & $\begin{array}{l}\text { Intrarun } \\
\text { precision } \\
(\mathrm{RSD} \%)\end{array}$ & $\begin{array}{l}\text { Interrun } \\
\text { precision } \\
(\text { RSD \%) }\end{array}$ & $\begin{array}{l}\text { Accuracy } \\
(\mathrm{RE} \%)\end{array}$ & $\begin{array}{c}\text { Short-term } \\
\text { stability (\%) }\end{array}$ & $\begin{array}{l}\text { Freeze-thaw } \\
\text { stability (\%) }\end{array}$ & $\begin{array}{c}\text { Recovery } \\
(\%)\end{array}$ \\
\hline Cyclo(Gly-Gly)/Gly-Gly & $1.1 / 0.9$ & $0.7 / 2.6$ & $4.7 / 7.7$ & $100 / 99$ & $97 / 98$ & $97 / 99$ \\
\hline $\begin{array}{l}\text { Cyclo(L-Ala-L-Ala) and cyclo(D-Ala- } \\
\text { D-Ala)/cyclo(L-Ala-D-Ala) }\end{array}$ & $1.1 / 0.7$ & $3.5 / 0.9$ & $-0.3 / 8.1$ & $99 / 101$ & $99 / 98$ & $99 / 99$ \\
\hline L-Ala-L-Ala and D-Ala-D-Ala/L-Ala-D-Ala & $1.3 / 1.1$ & $3.9 / 1.7$ & $6.6 / 2.9$ & $100 / 97$ & $101 / 100$ & $100 / 100$ \\
\hline Cyclo(L-Arg-L-Arg)/L-Arg-L-Arg & $1.5 / 0.5$ & $6.4 / 6.7$ & $3.9 /-0.3$ & $102 / 99$ & $101 / 99$ & $100 / 98$ \\
\hline Cyclo(L-Asp-L-Asp)/L-Asp-L-Asp & $1.0 / 1.1$ & $1.3 / 1.9$ & $5.1 / 2.1$ & $100 / 101$ & $100 / 98$ & $101 / 98$ \\
\hline Cyclo(L-Asp-L-Phe)/L-Phe & $1.1 / 1.5$ & $3.0 / 3.1$ & $2.2 / 2.3$ & $102 / 100$ & $98 / 98$ & $100 / 98$ \\
\hline L-Asp-L-Phe/L-Phe-L-Asp & $2.7 / 2.1$ & 9.9/1.9 & $2.3 / 0.3$ & $94 / 103$ & $99 / 98$ & $99 / 101$ \\
\hline Cyclo(L-Pro-L-Tyr)/L-Tyr & $4.7 / 1.9$ & $5.4 / 4.4$ & $0.7 / 6.4$ & $100 / 101$ & $93 / 94$ & $99 / 98$ \\
\hline L-Pro-L-Tyr/L-Tyr-L-Pro & $1.4 / 1.3$ & $4.5 / 2.0$ & $4.3 /-0.1$ & $98 / 98$ & $99 / 98$ & $99 / 98$ \\
\hline Cyclo(Gly-L-Phe)/L-Phe & $2.9 / 1.2$ & $1.4 / 4.0$ & $-4.2 / 1.8$ & $97 / 100$ & $100 / 100$ & $99 / 100$ \\
\hline Gly-L-Phe/L-Phe-Gly & $1.3 / 0.9$ & $3.4 / 2.7$ & $0.3 /-2.0$ & $98 / 101$ & $100 / 100$ & $103 / 98$ \\
\hline
\end{tabular}

and $0.001 \mathrm{mM}$ and thus are slightly lower than $0.005 \mathrm{mM}$ detected in this study, but they are in the same range. We determined a broader linear range for cyclo(L-Asp-L-Phe) (0.005 to $5.00 \mathrm{mM}$ ) compared to 0.5 to $10.0 \mu \mathrm{g} \mathrm{mL}^{-1}$ [14] (equates 0.002 to $0.038 \mathrm{mM}$ ) or 5 to $100 \mu \mathrm{g} \mathrm{mL}^{-1}$ [15] (0.02 to $0.38 \mathrm{mM}$ ).

LOQ was defined as the lowest concentration which could still be measured with a maximum of $20 \%$ RSD for precision and $\pm 20 \% \mathrm{RE}$ for accuracy. The minimal LOQ was identified for cyclo(L-Asp-L-Phe), L-Asp-L-Phe, cyclo(LPro-L-Tyr), and cyclo(Gly-L-Phe) with $0.05 \mathrm{nmol}$ per $10 \mu \mathrm{L}$ injection and ranged to $10.00 \mathrm{nmol}$ per $10 \mu \mathrm{L}$ injection for Gly-Gly and L-Tyr (Table 2).

The linear equations calculated in this study strongly varied depending on the substance (Table 2). In general, the slopes for all aromatic substances were higher than for most other used substances, due to the higher UV absorption of the aromatic ring. The correlation coefficient $R^{2}$ for each substance was greater than or equal to 0.9990 within the defined linear range, except for cyclo(Gly-Gly) and Gly-Gly with 0.9980 and 0.9989 , which are still acceptable values (Table 2).

3.3. Precision and Accuracy. The results for intrarun and interrun precision and accuracy are summarized in Table 3. The lowest relative standard deviation for intrarun precision was $0.5 \%$ for L-Arg-L-Arg. The highest RSD (\%) for intrarun precision was measured for cyclo(L-Pro-L-Tyr) with $4.7 \%$. For interrun precision the lowest RSD (\%) value was $0.7 \%$, detected for cyclo(Gly-Gly) and the highest RSD (\%) value was $9.9 \%$ for L-Asp-L-Phe.

For substances which showed higher measured concentration than true concentration, the highest relative error for accuracy was $8.1 \%$, detected for cyclo(L-Ala-D-Ala). The best accuracy was $0.3 \% \mathrm{RE}$, measured for L-Phe-L-Asp and Gly-L-Phe. For samples which showed lower measured concentration than true concentration, best accuracy was $-0.1 \%$ RE obtained for L-Tyr-L-Pro and highest RE (\%) value was $-4.2 \%$, measured for cyclo(Gly-L-Phe). For all other substances accuracy was between -4.2 and $8.1 \% \mathrm{RE}$.

3.4. Stability and Recovery. Data measured for short-term and freeze-thaw stability and for recovery are shown in Table 3. After short-term storage at $21^{\circ} \mathrm{C}$ for $24 \mathrm{~h}$ at least $97 \%$ of each substance were still detectable except for L-Asp-L-Phe, with $94 \%$ stability. For freeze-thaw stability also $97 \%$ or more were determined for all substances apart from cyclo(L-Pro-LTyr) and L-Tyr, with a stability of $93 \%$ and $94 \%$.

For all investigated DKPs, dipeptides and amino acids the recovery rate after heat treatment at $90^{\circ} \mathrm{C}$ for 10 min was at least $97 \%$ or greater. Thus, this procedure is efficient for enzyme inactivation in crude extract and all substances can be detected in sufficient amount.

\section{Conclusions}

In this work RP-HPLC methods were established for separation of seven DKPs from their corresponding linear dipeptides and in some cases the related amino acids within $15 \mathrm{~min}$ analysis time. This approach allows a rapid quantitative analysis of these molecules. Baseline separation with a peak resolution greater than 1.5 was achieved for separation of the six following DKPs from their corresponding linear dipeptides: cyclo(Gly-Gly), cyclo(DL-Ala-DL-Ala), cyclo(L-ArgL-Arg), cyclo(L-Asp-L-Phe), cyclo(L-Pro-L-Tyr), and cyclo(Gly-L-Phe). Furthermore, for the racemic DKP cyclo(DL-Ala-DL-Ala) and dipeptide DL-Ala-DL-Ala a method to separate the diastereomers was established and could be applied for enantioselective analysis of these 
molecules. Cyclo(L-Asp-L-Asp) could also be separated from its corresponding dipeptide, but not with baseline separation.

All methods were successfully validated in terms of sensitivity, linearity, intra- and interrun precision, accuracy, stability, and recovery, demonstrating their usefulness as analytical methods for the detection of DKPs, dipeptides, and amino acids in bacterial crude extract. The methodology could be extended to other analytes of interest and find application, for example, for a screening of strains exhibiting the ability to hydrolyze cyclic dipeptides to their corresponding linear dipeptides.

\section{Acknowledgments}

The authors want to thank the "Fachagentur Nachwachsende Rohstoffe e.V. (FNR)" for the financial support of this work within the joint project "PolyTe": polymeric surfactants from renewable resources with optimized performance properties (22012708). They acknowledge the support by "Deutsche Forschungsgemeinschaft" and Open Access Publishing Fund of Karlsruhe Institute of Technology. Moreover they thank Taros Chemicals GmbH \& Co. KG for providing DKPs.

\section{References}

[1] J. L. Johnson, W. G. Jackson, and T. E. Eble, "Isolation of L-leucyl-L-proline anhydride from microbiological fermentations," Journal of the American Chemical Society, vol. 73, no. 6, pp. 2947-2948, 1951.

[2] M. T. G. Holden, S. R. Chhabra, R. De Nys et al., "Quorumsensing cross talk: isolation and chemical characterization of cyclic dipeptides from Pseudomonas aeruginosa and other Gram-negative bacteria," Molecular Microbiology, vol. 33, no. 6, pp. 1254-1266, 1999.

[3] K. Ström, J. Sjögren, A. Broberg, and J. Schnürer, "Lactobacillus plantarum MiLAB 393 produces the antifungal cyclic dipeptides cyclo(L-Phe-L-Pro) and cyclo(L-Phe-trans-4-OH-L-Pro) and 3-phenyllactic acid," Applied and Environmental Microbiology, vol. 68 , no. 9, pp. 4322-4327, 2002.

[4] A. Lin, Y. Fang, T. Zhu, Q. Gu, and W. Zhu, "A new diketopiperazine alkaloid isolated from an algicolous Aspergillus flavus strain," Pharmazie, vol. 63, no. 4, pp. 323-325, 2008.

[5] A. C. Stierle, J. H. Cardellina, and G. A. Strobel, "Maculosin, a host-specific phytotoxin for spotted knapweed from Alternaria alternata," Proceedings of the National Academy of Sciences of the United States of America, vol. 85, no. 21, pp. 8008-8011, 1988.

[6] E. J. Dumdei, J. S. Simpson, M. J. Garson, K. A. Byriel, and C. H. L. Kennard, "New chlorinated metabolites from the tropical marine sponge Dysidea herbacea," Australian Journal of Chemistry, vol. 50, no. 2, pp. 139-144, 1997.

[7] F. Fdhila, V. Vázquez, J. L. Sánchez, and R. Riguera, "DDDiketopiperazines: antibiotics active against Vibrio anguillarum isolated from marine bacteria associated with cultures of Pecten maximus," Journal of Natural Products, vol. 66, no. 10, pp. 12991301, 2003.

[8] A. P. Einholm, K. E. Pedersen, T. Wind et al., "Biochemical mechanism of action of a diketopiperazine inactivator of plasminogen activator inhibitor-1," Biochemical Journal, vol. 373, no. 3, pp. 723-732, 2003.
[9] A. Lamm, I. Gozlan, A. Rotstein, and D. Avisar, "Detection of amoxicillin-diketopiperazine-2', 5' in wastewater samples.", Journal of Environmental Science and Health A, vol. 44, no. 14, pp. 1512-1517, 2009.

[10] U. Kertscher, M. Bienert, E. Krause, N. F. Sepetov, and B. Mehlis, "Spontaneous chemical degradation of substance P in the solid phase and in solution," International Journal of Peptide and Protein Research, vol. 41, no. 3, pp. 207-211, 1993.

[11] A. Kocijan, R. Grahek, D. Kocjan, and L. Zupančič-Kralj, "Effect of column temperature on the behaviour of some angiotensin converting enzyme inhibitors during high-performance liquid chromatographic analysis," Journal of Chromatography B, vol. 755, no. 1-2, pp. 229-235, 2001.

[12] E. Çubuk Demiralay and G. Özkan, “Optimization strategy for isocratic separation of $\alpha$-aspartame and its breakdown products by reversed phase liquid chromatography," Chromatographia, vol. 60, no. 9-10, pp. 579-582, 2004.

[13] V. George, S. Arora, B. K. Wadhwa, and A. K. Singh, "Analysis of multiple sweeteners and their degradation products in lassi by HPLC and HPTLC plates," Journal of Food Science and Technology, vol. 47, no. 4, pp. 408-413, 2010.

[14] K. Saito, M. Horie, Y. Hoshino, N. Nose, H. Nakazawa, and M. Fujita, "Determination of diketopiperazine in soft drinks by high performance liquid chromatography," Journal of Liquid Chromatography, vol. 12, no. 4, pp. 571-582, 1989.

[15] H. Y. Aboul-Enein and S. A. Bakr, "Comparative study of the separation and determination of aspartame and its decomposition products in bulk material and diet soft drinks by HPLC and CE," Journal of Liquid Chromatography and Related Technologies, vol. 20, no. 9, pp. 1437-1444, 1997.

[16] J.-D. Berset and N. Ochsenbein, "Stability considerations of aspartame in the direct analysis of artificial sweeteners in water samples using high-performance liquid chromatographytandem mass spectrometry (HPLC-MS/MS)," Chemosphere, vol. 88, no. 5, pp. 563-569, 2012.

[17] I. Furda, P. D. Malizia, M. G. Kolor, and P. J. Vernieri, “Decomposition products of L-aspartyl-L-phenylalanine methyl ester and their identification by gas-liquid chromatography," Journal of Agricultural and Food Chemistry, vol. 23, no. 2, pp. 340-343, 1975.

[18] C. Liu, H. Wang, Y. Jiang, and Z. Du, "Rapid and simultaneous determination of amoxicillin, penicillin $G$, and their major metabolites in bovine milk by ultra-high-performance liquid chromatography-tandem mass spectrometry," Journal of Chromatography B, vol. 879, no. 7-8, pp. 533-540, 2011.

[19] B. J. Compton, W. C. Purdy, and D. J. Phelps, "A highperformance liquid chromatographic technique for the determination of 2,5-piperazinedione in complex reaction mixtures," Analytica Chimica Acta, vol. 105, no. 1, pp. 409-412, 1979.

[20] K. Yokozeki, N. Usui, T. Yukawa, Y. Hirose, and K. Kubota, "Process for producing L-aspartyl-L-phenylalanine and its diketopiperazine," 0220028 B1, 1990.

[21] FDA, http://www.fda.gov/downloads/Drugs/GuidanceComplianceRegulatoryInformation/Guidances/UCM070107.pdf, 2001. 

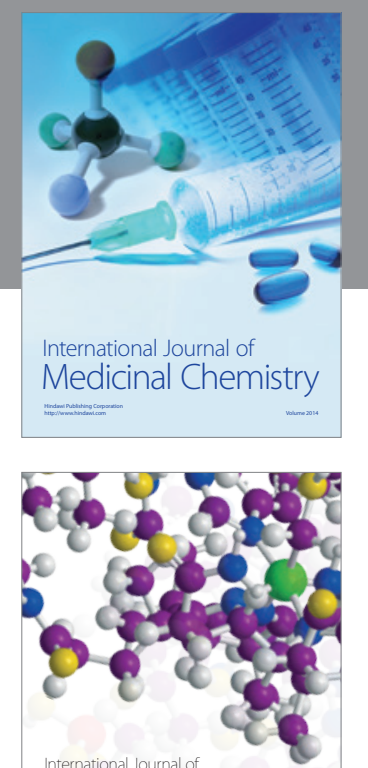

\section{Carbohydrate} Chemistry

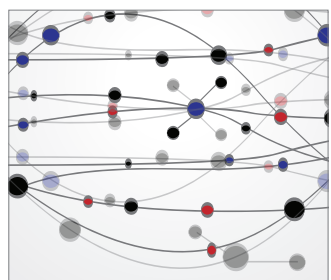

The Scientific World Journal
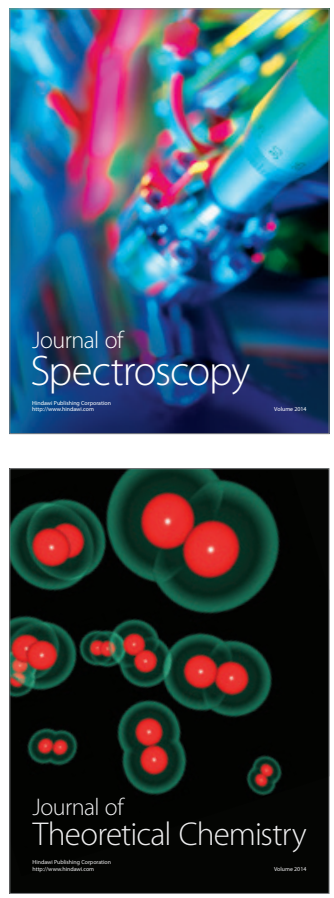
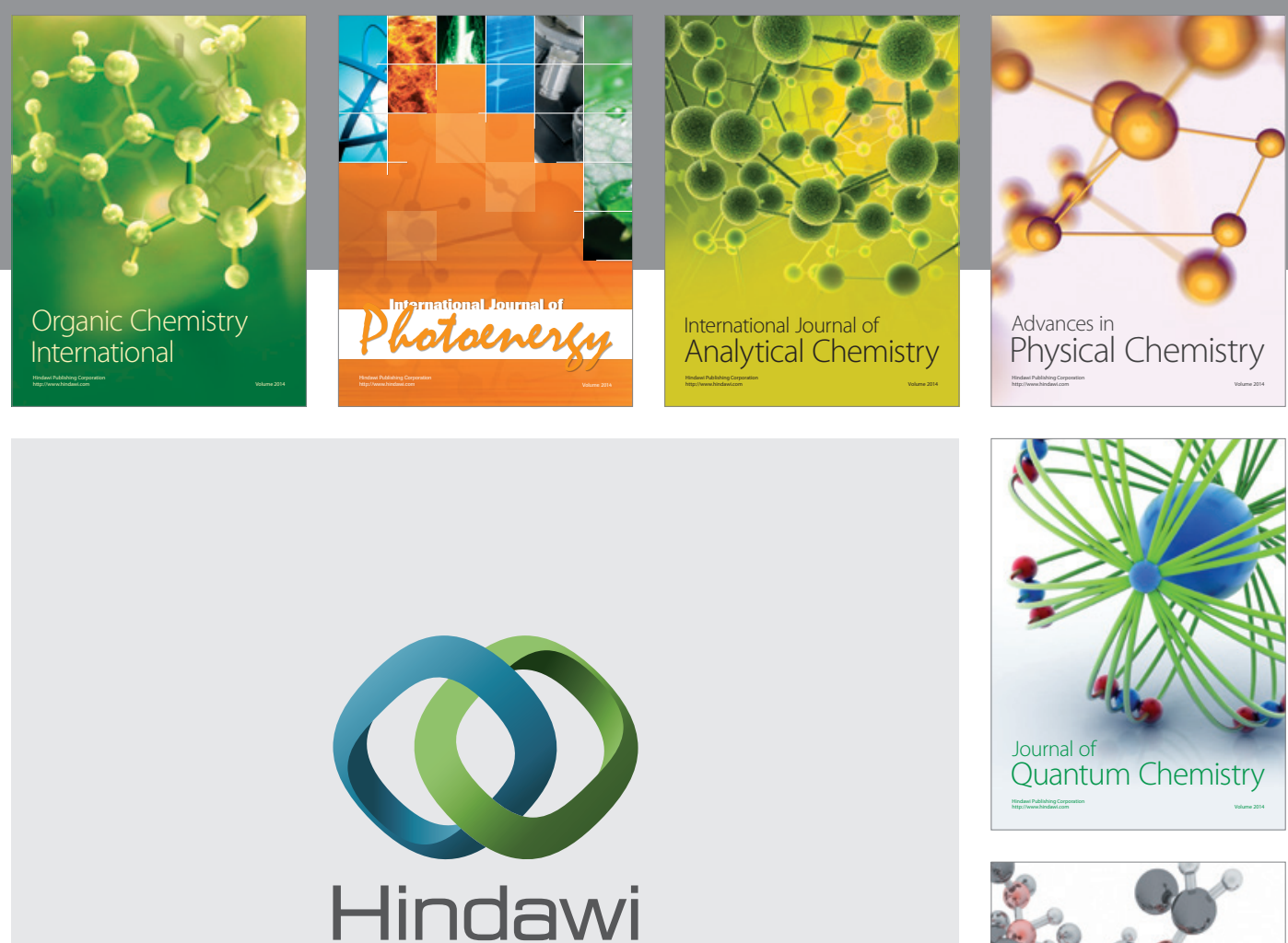

Submit your manuscripts at

http://www.hindawi.com

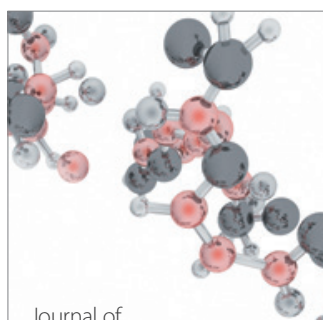

Analytical Methods

in Chemistry

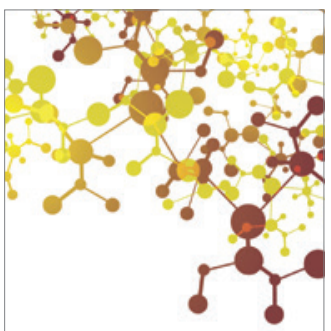

Journal of

Applied Chemistry

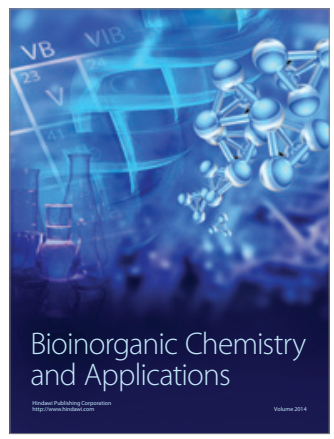

Inorganic Chemistry
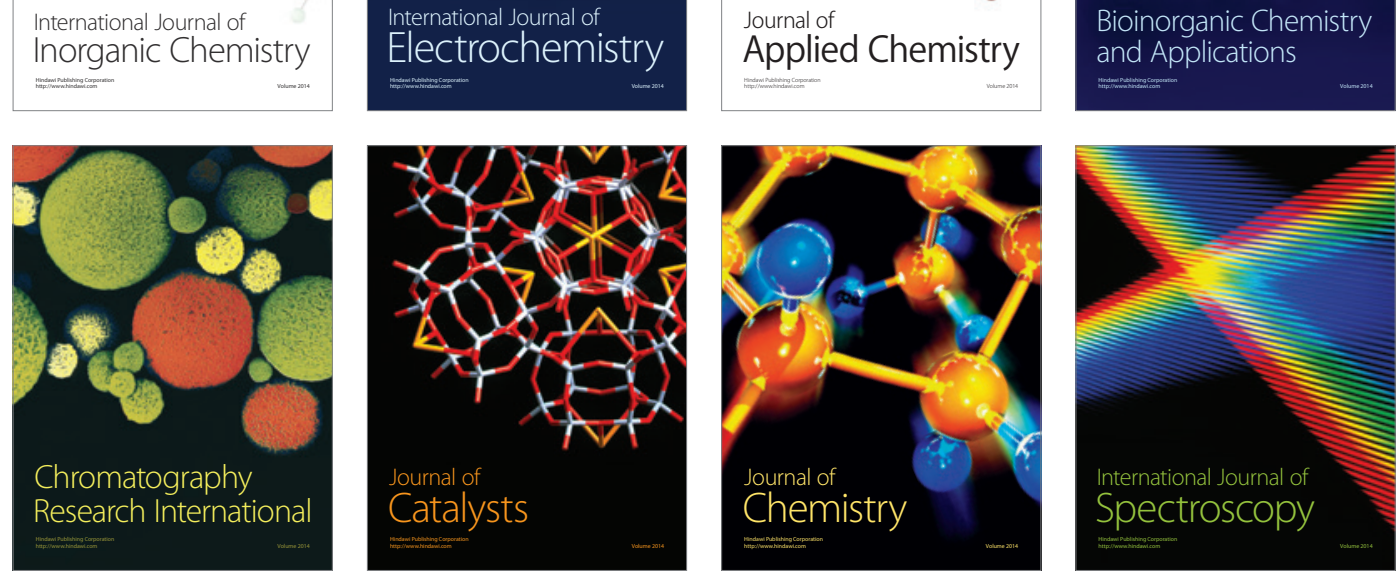